\title{
Local Real Estate Markets in Poland as a Network of Damped Harmonic Oscillators
}

\author{
S. Kulesza ${ }^{a, *}$ AND M. Belej ${ }^{b}$ \\ ${ }^{a}$ Faculty of Mathematics and Computer Science, Warmia and Mazury University in Olsztyn, \\ Słoneczna 54, 10-710 Olsztyn \\ ${ }^{b}$ Faculty of Geodesy and Land Management, Warmia and Mazury University in Olsztyn, \\ Prawocheńskiego 15, 10-720 Olsztyn
}

The paper deals with time series of housing prices on local real estate markets in Warszawa (WAW), Kraków (KRK) and Poznań (POZ) from 2006 to 2013 using a model of critically-damped harmonic oscillator to study underlying system dynamics. Performed analysis reveals the presence of housing bubble in 2007 that emerge from otherwise quasi-regular evolution around the equilibrium state. Time series of housing prices are fitted numerically to estimate important parameters of the system, for example: decay constant, delay time, and price equilibrium level, which help us to chose the leading market. Obtained results show reasonable matching of the model with housing prices in WAW and POZ, but less in KRK. The latter data, however, are found to agree well with the model of under-damped harmonic oscillator, which actually suggests that some trembling might occur in that market. Nevertheless, local real estate markets can be thought of as a system of interconnected damped harmonic oscillators with leading market in WAW that is about to change under aggregate macroeconomic fluctuations (exogenous factors) triggering changes in remaining markets.

DOI: 10.12693/APhysPolA.127.A-99

PACS: 05.70.Ln, 89.65.Gh, 89.75.Da

\section{Introduction}

The real estate markets are recognized worldwide to be of fundamental importance for national economy [1, 2]. In Poland, systemic transformation of 1990's has triggered the process of a revolutionary change in the property structure that, among others, released housing prices. From that moment the prices started to evolve remaining on the long-term, stable increase, interrupted occasionally by short-term bubbles. As a result, unprecedented rise in the housing prices has been observed in Poland within the last decade. However, the problem appeared that methods of modeling of the events in the real estate markets used so far turned out to be reliable only in case of slow changes [3-5], and they failed when the entire market goes out of its equilibrium [6-8].

To overcome the problem of description of this longterm trend disturbance, we have previously used the theory of discontinuous change (also known as the catastrophe theory) $[7,8]$. Catastrophic model takes assumption on extreme sensitivity of state variables (i.e. housing price) on even subtle fluctuations of exogenous factors (independent variables). In such a picture, the system evolution path follows a smooth curve remaining near its equilibrium state, and rarely jumps over the potential barrier to another equilibrium state.

Here, we deal with the same problem from the point of view of a dynamical system similar to damped harmonic oscillator pushed off a balance. Similar approach was

*corresponding author; e-mail: kulesza@matman.uwm.edu.pl adopted by Sandoval jr. et al. [9] to deal with a model of market dynamics with price expectations in order to analyze the reaction of financial markets to shocks. The system resembles a network of interconnected oscillators immersed in a multidimensional phase space. A set of points within the state space visited by the system establishes the evolution path. Long-term changes in the real estate prices suggest that otherwise regular evolution of such a system could be rarely disturbed by violent instabilities of structural origin.

\section{Critically-Damped Harmonic Oscillator}

Classical mechanics concerns a large variety of dynamical systems. Among them, systems with proportional negative feedback, which experience a restoring force when displaced from its equilibrium position, takes up a privileged position. Assume we have a block of mass $m$ attached to a linearly damped spring driven on the other side by an externally applied force $F_{\text {ext }}$ referred to as the driven damped harmonic oscillator. The Newton's law for this system reads:

$$
\ddot{y}+\frac{b}{m} \dot{y}+\frac{k}{m} y=\frac{F_{\text {ext }}}{m},
$$

where: $b$ is a damping (friction) coefficient, and $k$ is a spring constant. In general, total solution to that equation is a combination of two parts: a homogeneous solution $y_{h}$ which holds for equation with no external force, and a particular solution $y_{p}$ which needs to be proportional to a given $F_{\text {ext }}$.

Depending on the damping coefficient, the system can either oscillate with its amplitude going gradually to zero (under-damped system), or can decay straight to 
the equilibrium level with no oscillation (over-damped system). A transition point between these two regimes refers to as critically damped harmonic oscillations $(\mathrm{CDHO})$, used in this paper to model the time series of housing prices on local real estate markets. The analogy between housing market and CDHO model is drawn from observation seen in Fig. 1 that a steep rise in prices (non-stationary housing bubble) is in fact a temporary disturbance to otherwise stable (stationary) price evolution, which is followed by an asymptotic although not periodic relaxation to the equilibrium level. An exact analytical solution to the CDHO model takes up the form:

$$
y=y_{\mathrm{EQ}}+\left[A\left(t-t_{\mathrm{ABS}}\right)+B\right] e^{-\frac{t-t_{\mathrm{ABS}}}{\tau}},
$$

where: $y_{\mathrm{EQ}}$ is a long-term equilibrium level of the system, $t_{\mathrm{ABS}}$ is an absolute delay time, $\tau$ is a relaxation time (decay constant), whereas A and B - model constants that depend on the initial conditions. Relaxation time can be a measure of system inertia as it establishes a period of time in which the system returns to $e^{-1}$ of its initial disturbance. On the other hand, relaxation time is related with the mass and damping coefficient:

$$
\tau=-\frac{b}{2 m} \text {. }
$$

Hence, non-linear regression can be used in fitting the time series of studied prices with the $\mathrm{CDHO}$ equation to derive the measures of specific behavior of the housing market including, for example, its inertia, interconnectivity, delay in stimuli propagation etc.

\section{Results and discussion}

Time series of housing prices are plotted in Fig. 1 together with best fit curves obtained using the CDHO model. The details of estimated parameters, such as: absolute as well as specific time delays, $t_{\mathrm{ABS}}$, and $t_{0}$ respectively, relaxation constants $\tau$, and a long-term equilibrium levels $y_{\mathrm{EQ}}$, are specified in Table.

As mentioned previously, absolute time delay $t_{\mathrm{ABS}}$ describes the onset of the housing bubble with respect to an arbitrary time. Similar $t_{\mathrm{ABS}}$ values together with similar degree of price changes prove that time series are highly concurrent, and that housing bubbles appear almost simultaneously. According to data in Table, the WAW market reacts with the smallest delay (not longer than half a year) to those in KRK and POZ (3 and 3.6 quarters, respectively), which suggests that this housing market holds a dominant position. Any event in the dominant market is further propagating with specific delay $t_{0}$ to other subsystems triggering events of similar magnitude. If so, analyzed local housing markets can be thought of as a system of communicating vessels.

In general, relaxation time $\tau$ corresponds to a time interval required for an observable to decrease to $e^{-1} \approx$ 0.368 of its initial value. The longer relaxation time, the slower system return to the equilibrium state. On the other hand, reciprocal relaxation time can be associated with the system inertia, and with its sensitivity to aggregate fluctuations in independent variables. In case of

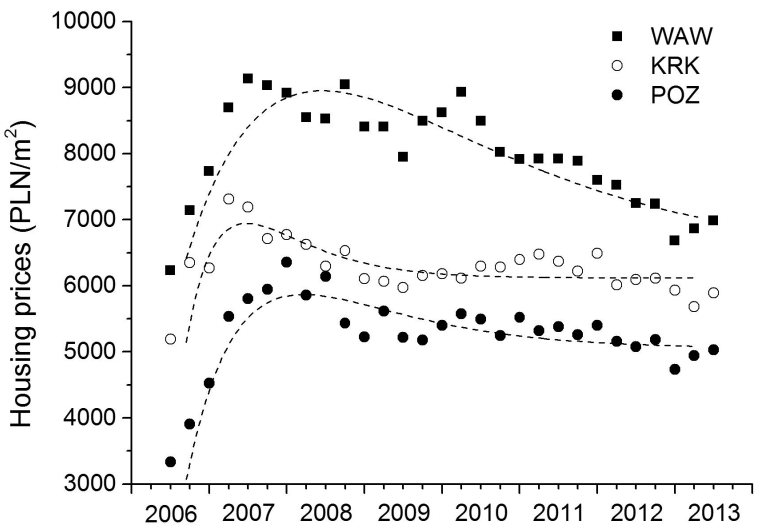

Fig. 1. Time-series of housing prices per square meter in, respectively: Warszawa (WAW, closed squares), Krakow (KRK, open circles), and Poznan (POZ, closed circles), from 2006 to 2013. Dashed lines correspond to numerical fit results obtained using the model of critically damped harmonic oscillator described in the forthcoming text.

TABLE

Absolute time delays $t_{\mathrm{ABS}}$ (with respect to arbitrary time series beginning), relative time delays $t_{0}$ (with respect to that of WAW), decay constants $\tau$, and asymptotic equilibrium level $y_{\mathrm{EQ}}$ of housing prices on local real estate markets obtained using the model of critically damped harmonic oscillator.

\begin{tabular}{c|c|c|c|c}
\hline \hline City & $t_{\mathrm{ABS}}$ [quaters] & $t_{0}$ [quaters] & $\tau$ [quaters] & $y_{\mathrm{EQ}}[\mathrm{PLN}]$ \\
\hline WAW & $1.7 \pm 0.1$ & $0.0 \pm 0.1$ & $7.4 \pm 0.1$ & $6451 \pm 1$ \\
KRK & $3.0 \pm 0.1$ & $1.3 \pm 0.2$ & $2.5 \pm 0.1$ & $6120 \pm 1$ \\
POZ & $3.6 \pm 0.1$ & $1.9 \pm 0.2$ & $4.2 \pm 0.1$ & $5057 \pm 1$
\end{tabular}

the housing market, relaxation time describes specific decay of time series of the prices towards equilibrium level $y_{\mathrm{EQ}}$ upon sharp disturbance (housing bubble). The markets characterized by lower $\tau$ values are found to be more sensitive to external stimuli, that is they exhibit larger price variations due to higher volatility. According to data in Table, the WAW market exhibits the longest decay time (approaching 2 years), whereas those in KRK and POZ exhibit time constants, respectively, 2.5 and 4.2 quarters. Such results suggest that WAW market is much more inert than the others, while that in KRK is the most volatile.

The most important sources of inertia in the housing markets is believed to follow from the market volume and the number of completed transactions. According to 2008 data supplied by the central statistical office of Poland, the market volumes in WAW, KRK, and POZ equaled to, respectively: 3271,761 , and 349 (mln PLN), whereas the numbers of transactions equaled to: 6922 , 2964 , and 1783 . As seen, these data are only partly correlated with the decay times, that is, the largest market decays at the slowest rate. However, in case of smaller markets the opposite holds true. Hence, the problem of 
the market inertia appears much more complex. This might be influenced by a variety of socio-economic aspects, such as increasing personal wealth, greater mobility, increasing availability of mortgages etc. On the other hand, migration to major cities should induce perpetuating demand for residential stock, and hence is expected to keep housing prices at higher levels. Aggregate influence of these factors might be the reason of observed difference in relaxation constants.

Long-term equilibrium level $y_{\mathrm{EQ}}$ defines the asymptotic limit, to which the system is approaching with elapsed time. In case of the housing markets, $y_{\mathrm{EQ}}$ values shown in Table again point at the dominant position of the housing market in WAW. Note that equilibirum prices in KRK are only 5 percent lower, which might suggest that WAW and KRK share the same equilibrium level. Unlike these housing markets, POZ has its own equilibrium level, which is more than 20 percent lower. To confirm the above assumption the phase-space diagrams of discussed systems are shown in Fig. 2 containing the plots of first differences of the housing prices drawn as a function of these prices.

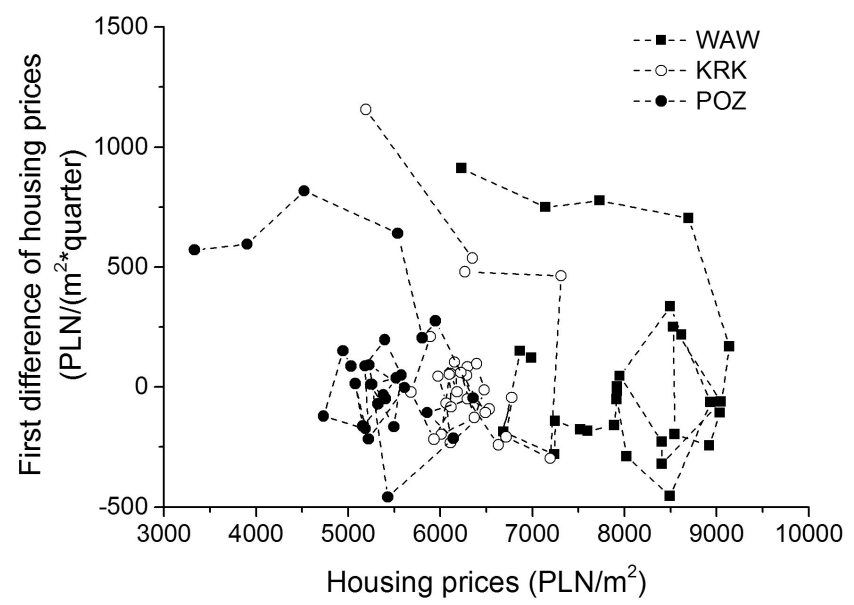

Fig. 2. Phase plots of time series of housing prices in WAW, KRK, and POZ. Note that each evolution path asymptotically goes to an equilibrium state.

In classical mechanics, the phase-space diagram for a damped oscillator spirals inwards indicating that the oscillator is losing its energy. At the end of this evolution path there is a point described as an "attractor" and the spiral shows that the system is trapped in a potential well from which it cannot escape. Likewise, phase diagrams seen in Fig. 2 exhibit the presence of three stable but separated equlibrium points (attractors). It is interesting to note that the evolution path of WAW initially spirals around the price level 8500 PLN (just after the bubble), but then jumps out of this shallow potential well and asymptotically converges with that of KRK. Again, this suggest a high degree of similarity between housing markets in WAW and KRK, and substantial difference from that in POZ.

Results obtained herein supports our previous assumption that local housing markets in Poland form a system

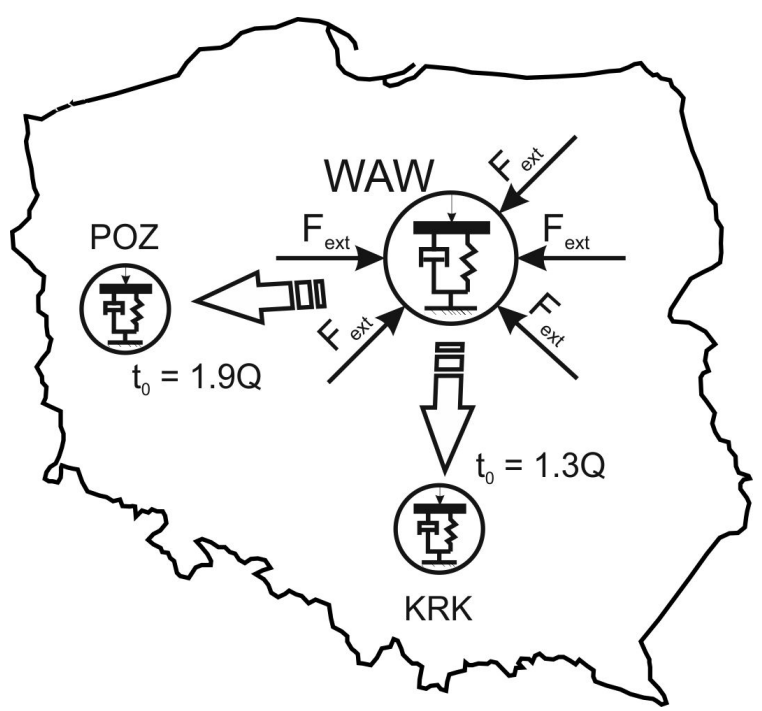

Fig. 3. Local real estate markets seen as a network of critically damped harmonic oscillators, in which any disturbance triggered by an external stimuli (aggregate macroeconomic fluctuations) firstly drives a market in WAW, and then propagates across the net (with the delay $\left.t_{0}\right)$.

of communicating vessels $[7,8]$ which can be represented by a network of interconnected harmonic oscillators. Schematic diagram of such a system is shown in Fig. 3. In this view, the WAW market takes up a dominant position, and reacts to events in the macroeconomic environment (exogenous factors). Created disturbance in housing prices propagates across the network to other markets, and triggers similar, although delayed changes. However, to confirm presented model, further investigation is neccessary that will consider other housing markets in Poland.

\section{Conclusions}

Results presented in the paper were obtained assuming that housing markets can be described similar to dynamical systems in physics, and more specifically similar to damped harmonic oscillators. Local housing markets in three major cities in Poland turn out to be highly inertial among other economic systems, that is they return to their equilibrium after being disturbed much longer than, for example, stock exchange. Typical relaxation time varies between 0.5 and 2 years. In addition, these markets also are possibly less volatile due to infrequent appearance of sudden events in the market (price bubbles).

Prices in local housing markets follow (with a slight delay) the dominant housing market in Warszawa concerning both the trend direction and degree of changes. Observed fluctuations are due to exogenous factors common to all housing markets. On the other hand, differences in estimated time constants, delays, and price equilibrium levels possibly have their origin in endogenous factors specific of each housing market. 


\section{Acknowledgments}

This work was supported by a grant from the National Science Centre (NCN) number DEC 2012/07/B/HS4/03267

\section{References}

[1] H. Selim, Expert Systems with Applications 36, 2843 (2009).

[2] D. Venclauskiene, V. Snieska, Economics and Management 14, 1026 (2009).

[3] R. Wisniewski, Wielowymiarowe prognozowanie wartosci nieruchomosci, Wydawnictwo Uniwersytetu Warminsko-Mazurskiego, Olsztyn 2007.

[4] I. Forys, Spoleczno-gospodarcze determinanty rozwoju rynku mieszkaniowego $w$ Polsce. Ujecie ilosciowe, Wydawnictwo Naukowe Uniwersytetu Szczecinskiego, Szczecin 2010.
[5] I. Forys, B. Batog, Wiadomosci Statystyczne 5, 36 (2013).

[6] R.N. Mantegna, H.E. Stanley, Ekonofizyka. Wprowadzenie, Wydawnictwo Naukowe PWN, Warszawa 2001.

[7] M. Belej, S. Kulesza, Folia Oeconomica Stetinensia 11, 61 (2013).

[8] M. Belej, S. Kulesza, Acta Phys. Pol. A 123, 497 (2013).

[9] L. Sandoval jr, I. de Paula Franca, arXiv:1103.1992, 2011. 